\title{
Coffee from Cultural Perspectives: Inventorying the Local Wisdom behind Coffee Industries in Wonosobo
}

\author{
Rifka Pratama ${ }^{1 *}$, Ariya $\mathrm{Jati}^{2}$, and Pramudya Lazuardi ${ }^{3}$ \\ ${ }^{1}$ English Department, Faculty of Humanities, Universitas Diponegoro, Indonesia \\ ${ }^{2}$ English Department, Faculty of Humanities, Universitas Diponegoro, Indonesia \\ ${ }^{3}$ English Department, Faculty of Humanities, Universitas Diponegoro, Indonesia
}

\begin{abstract}
As one of the potential worldwide exports and imports, coffee's economic and culinary values are undoubtedly outstanding. In Indonesia, the agricultural product has been increasingly prevalent and commercial. Research shows domestic coffee consumption reached 4.8 million bags of coffee beans in 2018-2019. As it continues to become more industrialized, it is also a part of nowadays' popular culture. However, cultural perspectives to coffee production and consumption are rarely research topic priorities. Putting the perspectives as the theoretical basis, the research aims to examine, elaborate, and inventory the manifestations of local wisdom as a cultural practice behind the coffee industries in Wonosobo. The data was taken by making field observations, conducting interviews with relevant interviewees, and reviewing related literature. The result of the research reaffirms that local wisdom as a cultural practice is reflected in the process of coffee production and consumption. It takes the form of several manifestations of culture, namely symbols, rituals, and values
\end{abstract}

\section{Introduction}

In the industry context, coffee has been more exposed to the economic and the culinary sector. In this case, coffee is an industrial commodity with a potential selling value. In addition, it is a drink that has been widely served for centuries and industrialized over time [1]. Although it may utilize various service, processing, and packaging methods, every social group has been familiar with the caffeinated drink. The variety, in turn, gives rise to different preferences among coffee connoisseurs. However, it is not a strictly segmented beverage unless it is related to the packaging, the types, or the serving methods. Each of the coffee drinkers drinks according to their respective experiences.

It is not that the economic and the culinary industry perspectives are no longer relevant. The two disciplines are undoubtedly fundamental. It is just that an overemphasis on them could position coffee as a mere economic commodity. The extensive coffee production, starting from planting, preserving, harvesting, to processing, must have been neither merely an economic nor culinary phenomenon. The gradual and comprehensive process of coffee

* Corresponding author: pratamarifka@live.undip.ac.id 
preservation implies a connection with interdisciplinary approaches. The dichotomy of traditional and modern coffee processing and preservation methods, for example, can indicate the interdisciplinary correlations. The terms "traditional" and "modern" deal with differences in concepts and behaviour within socio-cultural contexts.

Wonosobo is potentially suitable for developing coffee plantations in Central Java Province as one of the regencies with supportable natural resources. Coffee had become a mainstay plant in the late 1800s in Wonosobo [2]. In 1819, Java Coffee, a mass-scale coffee factory, was established. It was located in the district of Sapuran. The claim is founded in line with the emergence of many local coffee processors and consumption industries in the region nowadays. It can take the form of either medium-scale or home industries. Various local coffee shops with their respective product differentiations begin to open in terms of the coffee consumption industry. The phenomena appear to be very economical. This, however, is also very likely related to other disciplines such as sociology and culture.

The cultural perspectives on the development of the coffee industry in Wonosobo concern the concepts shared by and the behaviours of the stakeholders and other individuals involved. The perspectives are also very likely related to the behaviours of coffee drinkers and connoisseurs. Therefore, the Javanese cultural context, the local wisdom, and the religious views shared by the people of Wonosobo are hypothetically correlated with the coffee industry. It can be explored from the views of industrial stakeholders and the other associated parties regarding the planting, the preservation, the harvest, the processing, and the consumption of coffee.

This research aims to examine, elaborate, and inventory the manifestations of local wisdom as a cultural practice within the coffee industries in Wonosobo Regency. The research involves relevant parties and scientific sources. It includes the stakeholders and other individuals involved in the coffee industry, the public, and the experts. Exploring the local wisdom is expected to deliver a coherent explanation affirming that a cultural perspective on coffee is in all probability. The focus of the research is based on the following concerns: (1) whether or not the coffee industry is a cultural phenomenon, (2) how it is a cultural phenomenon, and (3) what local wisdom exists in the coffee industries.

\section{Methods}

The research data was collected by visiting and observing directly the loci and the corresponding objects, conducting interviews with relevant interviewees, and studying literature. The loci are coffee plantations, home coffee industries, and coffee shops in the Wonosobo regency. The interviews were carefully conducted with local coffee farmers, coffee processors, coffee shop owners and managers, and coffee drinkers and connoisseurs. The data collection focuses on three aspects in the coffee industry, namely (1) production, (2) packaging, and (3) consumption. The secondary sources taking the form of cultural theories and approaches are utilized to explore the local wisdom reflected on the subject. After the data are collected, several stages of processing are carried out. This includes transcribing the interview data, focus group discussions, thorough study, sorting the relevant information, and conducting scientific analysis. The research is qualitative, through which the data are analyzed employing the mentioned methods. They are the systematic constructs that contain the researchers' interpretations and descriptions of the collected data [3]. 


\section{Result and Discussion}

\subsection{Coffee from Cultural Perspectives}

Having a long history, philosophy, and a variety of service procedures, coffee represents a cultural matter. The term culture can be interpreted using several keywords: "culture is divided; it is acquired, not innate; the elements make up a complex whole; it is passed from one generation to the next" [4]. The term ngopi is familiar and popularly understandable to Indonesians. It may simply mean drinking coffee. However, it is more than only drinking coffee in practice. In this context, coffee is a drink served amid the social interactions among individuals. It usually takes the form of talks, chats, conversations, or discussions. The situations ordinarily do not require a certain level of seriousness. The use of the term ngopi itself suggests the expectation of a relaxed and friendly situation within the ongoing social interaction. Ngopi is, therefore, not only a culinary phenomenon. It is sociological, symbolic, and traditional.

Tischler defines culture as "all those humans learn to do, to use, to produce, to know, and to believe as they grow to maturity and live out their lives in the social groups to which they belong" [5]. Humans, the subject in the definition, have long studied, processed, and made coffee with all its complexities a part of life. In addition, Bodley points out the existence of "three basic components of culture, namely: what people think, what they do, and the material products they produce" [6]. Referring to the concept, ngopi and the coffee industry are covered by definition to some degree. Both reflect thoughts, activities, and materials processed by humans. From the cultural perspective, the complexity of coffee includes traditions in the process of production and consumption. It deals with the embedded symbolic meanings as well. At this point, coffee can be distinctive in one another in which geographical and socio-cultural contexts are influential. Locality, thus, is another crucial aspect in emphasizing coffee and coffee industries as a cultural matter since it is where uniqueness typically emerges.

Besides being studied, transmission is another key to the characteristics of culture [7]. The process of cultural transmission has various methods. A local community's understanding of coffee and its complexity is usually obtained through oral stories from generation to generation and learning experiences. Over time, the knowledge improves within the ongoing social interactions among individuals involved in the subject. Various concepts about coffee are also often influenced by distinctive conscious beliefs that exist in a social group. Lebron states, "Culture is the unique characteristic of a social group; the values and norms shared by its members set it apart from other social groups and are influenced by conscious beliefs" [8]. The diverse understanding and treatment make coffee a cultural phenomenon.

Hofstede et al. stated that symbols, heroes, rituals, and values are cultural manifestations. The four say it differently. Citing the theory,

"Symbols are words, gestures, pictures, or objects that convey a particular meaning that is recognized as such only by those who share the culture. Heroes are persons, alive or dead, real or imaginary, who possess characteristics that are highly prized in culture and therefore serve as models for behaviour. Rituals are collective activities that are technically superfluous to reach desired ends but that, within a culture, are considered socially essential. They are therefore carried out for their own sake. Values are broad tendencies to prefer certain states of affairs over others. Values are feelings with an added arrow indicating a plus and a minus side" [9]. 
The four cultural manifestations may differ in portions from one another. One might be more dominant than the other in the context of coffee production. Regarding the symbols, there are various kinds of specific terms or technical words used in the coffee industry about which not everyone understands. These terms convey particular meanings and are ordinarily well-recognized nothing but by those involved in the coffee industry. The individuals involved in the industry can be exclusive as they employ symbols understood within their cultural context, the coffee industry. The use of symbols in the coffee industry can be found in various related aspects of the process. It covers the stages of cultivation, the processing, the packaging, and the service and consumption methods.

From a cultural perspective, the planting, the processing, and the service methods of coffee can represent manifestations of rituals. Customs, habits, and steps are there to become standard during the activities. The subjects involved in the industrial processes must comply with the standards. In terms of coffee service methods, such as standardized doses, types, tools, and moods often remain essential requirements for the best taste. Still, coffee drinkers have their preferences when it comes to tasting. The existence of specific standards clearly shows that coffee is closely related to culture, taking the form of rituals. The procedures and methods referred to may be used to standardize the quality.

Nevertheless, it would not exclude the social contexts of the phenomenon. Standardization in the cultivation, the processing, the packaging, and the consumption of coffee is very likely dealt with the social agreements of the subjects involved. The coffee industry is reflecting the concepts of culture. In this case, the locality of the product is frequently a significant determiner.

\subsection{The Local Wisdom behind Coffee Industries in Wonosobo Regency}

Wonosobo Regency, Central Java Province is known for its mountainous areas and its potentially good soil fertility [10]. In addition to vegetable farming and staple food, the small to medium-scale coffee plantation is currently a prospective alternative sector in the region. Along with the increasing demand from the local and the external markets, the production of coffee has become more deliberate. The people of Wonosobo have long been familiar with various agricultural concepts. They have been living around culturally agricultural situations. Most of the areas are rural, making agriculture one of the livelihoods for the majority of the people. To some extent, this is additionally a kind of a trademark.

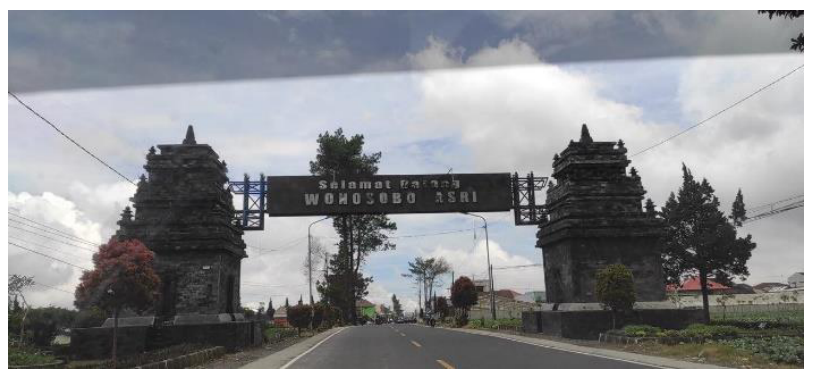

Fig. 1. Welcoming Gate of Wonosobo Regency.

The cultural phenomena within the coffee industry become more clearly visible with the reflections of the local wisdom in the ongoing industrial activities. Sartini states, "local wisdom can be understood as local ideas that are wise, full of wisdom, of good value, embedded and followed by members of the community" [11]. Nakorntap et. al. added, 


\begin{abstract}
"Local wisdom is basic knowledge gained from living in balance with nature. It is related to culture in the community accumulated and passed on. This wisdom can be both abstract and concrete, but the important characteristics are from experiences or truth gained from life. The wisdom from real experiences integrates the body, the spirit, and the environment. It emphasizes respect for elders and their life experiences. Moreover, it values morals more than material things" [12].
\end{abstract}

Local wisdom is part of the discussion of culture for several reasons. To begin with, it has various manifestations and is very often rooted in exclusive contexts. Exclusivity means that it emerges from one distinct social-cultural context. Second, it is an existence that binds or is followed by the community. Third, it is passed down, transmitted, and studied. Fourth, similar to the concepts of culture, it has something to do with beliefs, moralities, and wisdom. Utilizing the existing concepts on culture, there are various manifestations of local wisdom behind the coffee industry in Wonosobo. The reflections and manifestations referred to address several aspects in the coffee industry, namely (1) planting, (2) processing, (3) packaging, and (4) consumption.

\title{
3.2.1 Local Wisdom in the Process of Coffee Production
}

During During the planting process, coffee farmers in Wonosobo apply some principles rooted in local wisdom. These principles are reflected in the belief shared by the local coffee farmers. Farming, according to them, is a form of religious worship, and it is a socially valuable activity that empowers the local people with employment opportunities. The belief originates from the values shared in the practised religion. Religion is the source of value, but it does not eliminate the existence of the local wisdom within. The religious values are inherited among the farmer families or studied in the religious forums in the neighbourhood. A typical and traditional transmission method shows this as a reflection of the local wisdom. Including the reflection of wisdom and morality, which is in line with the concepts of local wisdom.

The local wisdom in coffee planting activities does not only concern values or philosophical aspects. There are also other technical matters reflecting the idea of local wisdom during coffee production. The first is the involvement of women as agricultural workers. According to Haji Ali, a local coffee farmer, women tend to perform careful and tidy work, likewise in another process. This phenomenon does not suggest it is not because women have never been involved in agricultural activities. Preferably, it is related to the motives behind it. The second technical aspect concerns the use of pranata mangsa, a classification of the traditional Javanese planting periods, by the coffee farmers [13]. The concept is considered relevant and reliable in most of the agricultural situations in the area. Apart from that, the concept of pranata mangsa is also related to the wisdom of nature. The third reflection is on the concepts, the principles, and the nature-based planting techniques applied by the local farmers. Organic fertilizer is more frequently used than chemical ones. The process of decomposing and using organic fertilizers is done traditionally. This procedure continues to be preserved, although chemical fertilizers are used in some ways. Furthermore, the local wisdom takes the form of the use of traditional and modified agricultural tools. More specifically, these tools are a sickle, hoe, a modified motorcycle for transporting grass, a coffee peeler, a resting hut, and so on. 


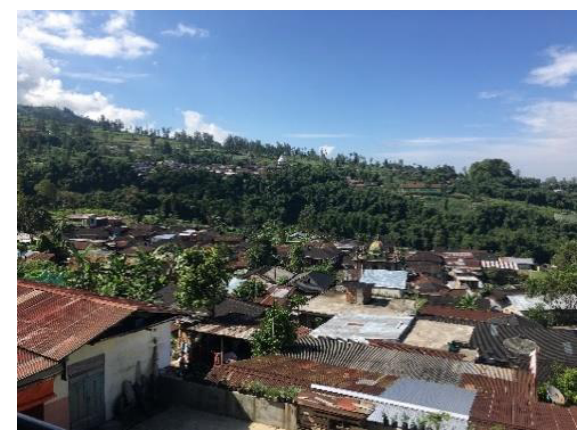

Fig. 2. Bakalan Village.

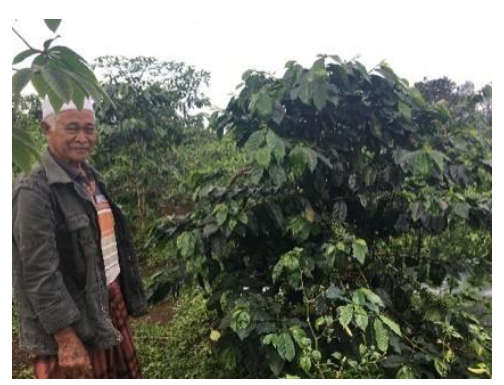

Fig. 4. Haji Ali (A local coffee farmer).

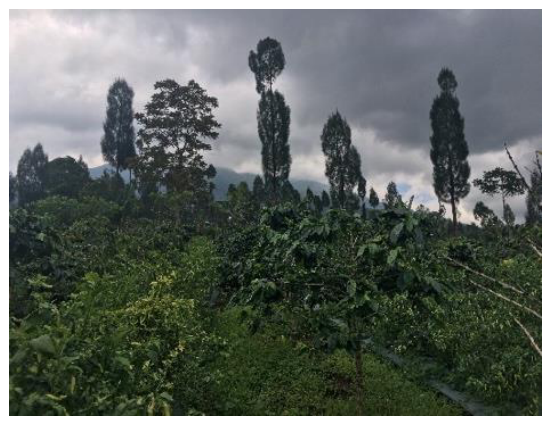

Fig. 3. Coffee Plantation in Bakalan Village.

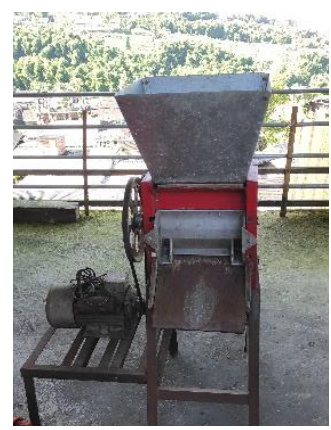

Fig. 5. Coffee Peeler Machine.

\subsubsection{Local Wisdom in the Process of Coffee Packaging and Consumption}

The packaging and serving aspects are very close to the finishing stage in the industrial process. These two stages are as necessary as the planting stage. Packaging and serving allow the creation and the engineering processes to happen to engage consumers [13]. In the context of the study, the packaging is concerned with product naming. In this case, the coffee producers in Wonosobo brand their products with an emphasis on the locality. The choice of words used in the product label typically derives from the village's name where the coffee production activities take place. In addition, the coffee producers use several tourism trademarks such as the name and the picture of Mount Sumbing. In a more philosophical view, each coffee producer expresses a purpose in naming their products. There is an ideal to be expected. Here are three examples of coffee brands in Wonosobo: 


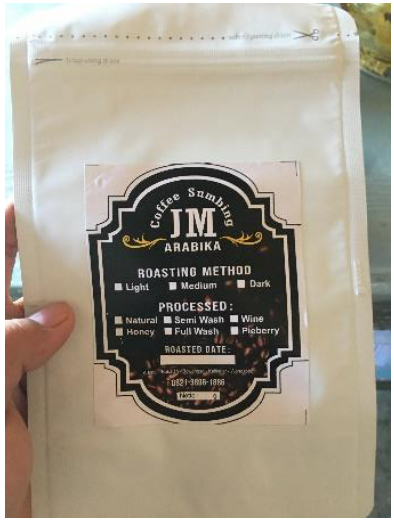

Fig. 6. The Arabika Kopi JM (Jaminan Mutu).

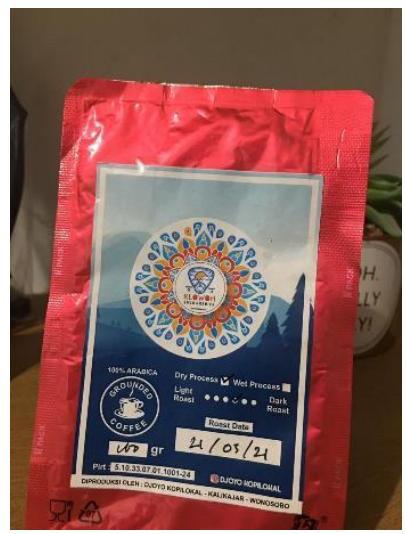

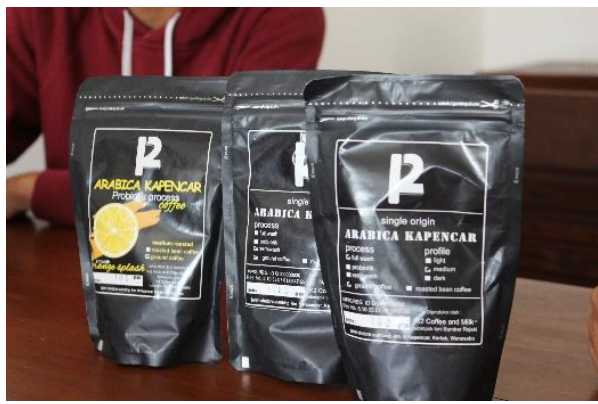

Fig. 7. The Arabica Kopi K2 Kapencar.

Fig. 8. The Djoyo Kopi Lokal Arabika Klowoh.

The JM (Jaminan Mutu) coffee brand owner revealed that the naming rests on his aspirations to maintain the quality of the products. The owner of the Djoyo Kopi Lokal (local coffee) brand stated that locality creates distinctiveness. Furthermore, the K2 Kapencar coffee brand owner said that they wanted their products to reach the best quality (as the peak of K2) while still being aware that there might be other best products around. All of the examples show that the naming of the coffee products affects at least two aspects, namely the emphasis on the locality and the philosophy.

Various groups of society additionally retain a distinctive concept in terms of serving and drinking coffee methods. The term ngopi, as previously mentioned, is one of the subject matters. People expect a relaxed and intimate situation to the word ngopi. This is marginally contradictory when one uses the term "drinking coffee" which implies the contrary tendency. The people of Wonosobo are familiar with the term ngopi in both traditional and contemporary popular contexts. Among the reflection of the local wisdom is the moment of togetherness as the moral of the activities, the unique tools and methods of serving, sides, and so on. For some coffee drinkers, the use of modern tools in serving coffee may have become commonplace. The other may traditionally serve coffee in terms of both the tools and the methods. All of the mentioned phenomena are likely related to the locality where the coffee is produced and served. Therefore, the reflection of the local wisdom appears. 


\section{Conclusion}

Local wisdom as a cultural practice behind the coffee industry in Wonosobo is reflected. In the stages of production, the local wisdom that can be inventoried includes (1) the existence of religious beliefs and the transmissions of the values among the stakeholders, (2) the motives behind the involvement of women as coffee planters, (3) the use of traditional concepts and planting tools, and (4) the concept of traditional planting periods applied by the farmers. In terms of packaging and serving, the local wisdom comprises (1) the philosophy of the product naming (2) emphasizing locality as part of product branding (3) the use of particular terms to refer to coffee drinking activities (4) distinctive sides, and (5) the unique tools and the methods of serving. All of the local wisdom examined is also in line with the cultural manifestations, namely symbols, rituals, and values.

\section{References}

1. S. Topik, The World Coffee Market in the Eighteenth and Nineteenth Centuries, from Colonial to National Regimes, (2004)

2. A.M. Irianto, Sejarah Wonosobo, (2008)

3. S. Ospina, Qualitative Research, (2004)

4. H.L. Tischler, Introduction to Sociology, (2010)

5. H.L. Tischler, Introduction to Sociology, (2010)

6. A. Lebrón, What is Culture?, Merit Research Journal of Education and Review Vol. 1(6), 126-132, (2013)

7. W.A. Haviland, H.E.L. Prins, Walrath, B. McBride, The Essence of Anthropology, (2015)

8. A. Lebrón, What is Culture?, Merit Research Journal of Education and Review Vol. 1(6), 126-132, (2013)

9. G. Hofstede, G.J. Hofstede, M. Minkov, Cultures and Organization (Software of the Mind) - Intercultural Cooperation and Its Importance for Survival, 8-9, (2010)

10. L.F.L. Pratiwi, S.Hardyastuti, L.R. Waluyati, Profitability and Farmers Conservation Efforts on Sustainable Potato Farming in Wonosobo Regency. Ilmu Pertanian (Agricultural Science), 1(1), 31-36 (2016)

11. S. Sartini, Menggali kearifan lokal Nusantara: Sebuah kajian filsafati. Jurnal filsafat, 14(2), 111-120, (2004)

12. M.R. Mungmachon, Knowledge and local wisdom: Community treasure. International Journal of Humanities and Social Science, 2(13), 174-181, (2012)

13. M.K. Zaki, K. Noda, K. Ito, K. Komariah, S. Sumani, M. Senge, Adaptation to Extreme Hydrological Events by Javanese Society through Local Knowledge. Sustainability, 12(24), 1-11 (2020) 